\title{
Late results of the Cox-maze IV procedure in patients undergoing coronary artery bypass grafting
}

Matthew R. Schill, MD, Farah N. Musharbash, Vivek Hansalia, BEng, Jason W. Greenberg, BS, Spencer J. Melby, MD, Hersh S. Maniar, MD, Laurie A. Sinn, BSN, RN, Richard B. Schuessler, PhD, Marc R. Moon, MD, and Ralph J. Damiano, Jr, MD

\section{ABSTRACT}

Objective: Most patients with atrial fibrillation (AF) undergoing cardiac surgery do not receive concomitant ablation. This study reviewed outcomes of patients with AF undergoing Cox-maze IV (CMIV) procedure with radiofrequency and cryoablation and coronary artery bypass grafting $(\mathrm{CABG})$ at our institution.

Methods: Between the introduction of radiofrequency ablation in 2002 and 2015, 135 patients underwent left- or biatrial CMIV with CABG. Patients undergoing other cardiac procedures, except mitral valve repair, or who had emergent, reoperative, or off-pump procedures were excluded. Eighty-three patients remained in the study group after exclusion criteria were applied. Freedom from atrial tachyarrhythmias (ATAs) was ascertained using electrocardiogram, Holter monitor, or pacemaker interrogation at 1 to 5 years postoperatively.

Results: Operative mortality was 3\%. Freedom from ATAs at 1 year in the CMIV group was $98 \%$, with $88 \%$ off antiarrhythmia drugs. Freedom from ATAs and antiarrhythmia drugs was $70 \%$ at 5 years.

Conclusions: The addition of CMIV to CABG resulted in excellent freedom from ATAs at 1 to 5 years. These patients are at increased risk for nonfatal complications compared with others undergoing concomitant surgical ablation. (J Thorac Cardiovasc Surg 2017;153:1087-94)

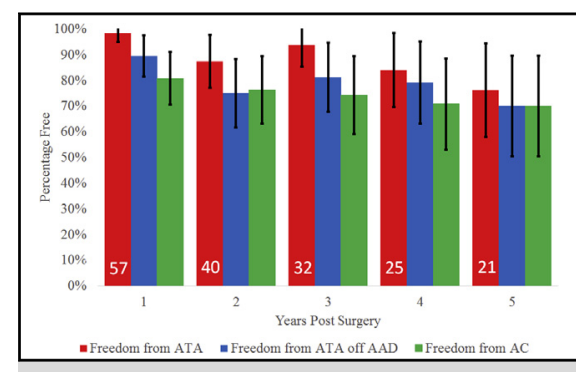

Long-term rhythm follow-up for patients undergoing Cox-maze IV procedure with coronary artery bypass grafting.

\section{Central Message}

Adding a Cox-maze IV procedure to coronary bypass surgery results in excellent freedom from atrial tachyarrhythmias.

\section{Perspective}

Despite the known effectiveness of surgical ablation for atrial fibrillation, most patients with atrial fibrillation undergoing heart surgery do not receive concomitant ablation. Our findings show that the addition of a Cox-maze IV procedure to coronary artery bypass surgery is associated with excellent freedom from atrial tachyarrhythmias.

See Editorial Commentary page 1095.

See Editorial page 1085 .
From the Division of Cardiothoracic Surgery, Washington University School of Medicine, Barnes-Jewish Hospital, St Louis, Mo.

M.R.S. is supported by National Institutes of Health grant No. T32-HL007776. R.J.D. is supported by National Institutes of Health grant No. R01-HL032257.

Read at the 42nd Annual Meeting of The Western Thoracic Surgical Association, Waikoloa, Hawaii, June 22-25, 2016.

Received for publication June 22, 2016; revisions received Dec 7, 2016; accepted for publication Dec 28, 2016; available ahead of print Feb 7, 2017.

Address for reprints: Ralph J. Damiano, Jr, MD, Washington University School of Medicine/Barnes-Jewish Hospital, Ste 3108 Queeny Tower, 1 Barnes-Jewish Hospital Plaza, St Louis, MO 63110 (E-mail: damianor@wustl.edu). $0022-5223 / \$ 36.00$

Copyright $\odot 2017$ by The American Association for Thoracic Surgery http://dx.doi.org/10.1016/j.jtcvs.2016.12.034
Coronary artery bypass grafting $(\mathrm{CABG})$ is a very common procedure. During the past decade, almost 1.5 million primary CABG operations were performed at institutions reporting data to the Society of Thoracic Surgeons (STS)

Scanning this QR code will take you to a supplemental video for the article.

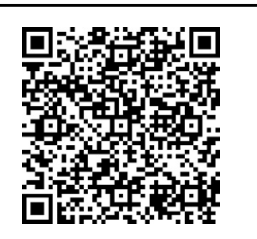




$$
\begin{aligned}
& \text { Abbreviations and Acronyms } \\
& \begin{aligned}
\text { AAD } & =\text { anti-arrhythmia drugs } \\
\text { AC } & =\text { anticoagulation } \\
\text { AF } & =\text { atrial fibrillation } \\
\text { ATA } & =\text { atrial tachyarrhythmias } \\
\text { CMIV } & =\text { Cox-maze IV } \\
\text { CABG } & =\text { coronary artery bypass grafting } \\
\text { STS } & =\text { Society of Thoracic Surgeons }
\end{aligned}
\end{aligned}
$$

database. $^{1}$ A significant proportion of patients undergoing CABG have been diagnosed with atrial fibrillation (AF) preoperatively. Current multispecialty consensus guidelines support surgical ablation for $\mathrm{AF}$ at the time of cardiac surgery unless the addition of surgical ablation at the hands of the operating surgeon will add significant risk, even in asymptomatic patients. ${ }^{2}$ Despite the evidence supporting concomitant surgical ablation, in the most recent published analysis of the STS database, only $28 \%$ of patients with preoperatively diagnosed $\mathrm{AF}$ undergoing $\mathrm{CABG}$ received concomitant surgical ablation. ${ }^{2}$

There have been numerous reports of concomitant surgical ablation in the literature. Our center has recently reported results of the Cox-maze IV (CMIV) procedure in patients undergoing diverse concomitant procedures. ${ }^{3-5}$ In patients undergoing mitral valve surgery, concomitant surgical ablation is supported by a multicenter randomized controlled trial. ${ }^{6}$ Our group has previously reported outcomes of the Cox-maze III procedure combined with $\mathrm{CABG}$ compared with $\mathrm{CABG}$ alone, ${ }^{7}$ but we have not done so since the introduction of radiofrequency ablation devices more than a decade ago.

In high-volume centers, the additional risk associated with concomitant surgical ablation appears to be low. Ad and colleagues ${ }^{8}$ stratified patients undergoing surgical ablation by European System for Cardiac Operative Risk Evaluation and found no difference in long-term survival and comparable return to sinus rhythm. Ad and colleagues ${ }^{9}$ also performed a propensity-matched study of Cox-maze III combined with aortic valve replacement and/or CABG and found longer cardiopulmonary bypass time, a higher risk of pacemaker implantation, and similar survival in the Cox-maze III group. Ad and colleagues ${ }^{9}$ also reported $94 \%$ freedom from $\mathrm{AF}$ at 12 months and $81 \%$ freedom from $\mathrm{AF}$ and antiarrhythmia drugs (AADs). This series included 47 patients who underwent a Cox-maze III procedure with CABG. Pokushalov and colleagues ${ }^{10}$ and Cherniavsky and colleagues $^{11}$ have recently shown a significant improvement in freedom from AF measured by implantable loop recorders in patients undergoing surgical ablation compared with CABG alone.

The objective of this study was to review the results of combined CMIV and CABG since the introduction of radiofrequency ablation devices in 2002 . We hypothesized that our rate of major complications would be similar to the rates published in the literature and that the long-term effectiveness of surgical ablation concomitant with CABG would be similar to the results reported by others.

\section{METHODS \\ Data Collection}

This study was approved by the Washington University Biomedical Institutional Review Board. The institutional review board provided waiver of consent for all patients in the CMIV-CABG group. Preoperative demographic data, operative details, and perioperative results were concurrently collected in our institutional STS quality improvement database using STS definitions for complications. Rhythm follow-up data were concurrently collected in our institutional maze outcomes research database. Missing data were obtained using chart review and contact with patients and their referring physicians when needed.

\section{Patient Population}

From March 2002 to July 2015, 135 patients underwent left- or biatrial CMIV with concomitant CABG. A flow diagram depicting the selection of the patient population is shown in Figure 1. During the same time period, 586 total patients with a history of AF underwent CABG. Of these patients, 425 received no ablation procedure, 23 received pulmonary vein isolation, and 3 received right atrial ablation only. Patients undergoing other concomitant cardiac procedures, with the exceptions of patent foramen ovale closure and mitral valve repair for ischemic mitral regurgitation, patients undergoing reoperative cardiac surgery, patients with no recorded left ventricular ejection fraction, and patients undergoing emergent procedures were excluded. Mitral valve repair and patent foramen ovale closure were included because these procedures require left atriotomy and add little operative time or complexity when CABG and CMIV are performed. After the application of exclusion criteria, there were 83 patients in the CMIV-CABG group. Eight patients underwent only the left atrial CMIV lesion set and 75 patients underwent a biatrial CMIV procedure.

\section{Surgical Procedure}

In the CMIV-CABG group, either the left- or biatrial CMIV procedure was performed via a median sternotomy as our group has previously described. ${ }^{12,13}$ Most patients underwent a biatrial Cox-maze procedure; an isolated left atrial procedure has been reserved for patients with recent onset of paroxysmal AF. The patient was positioned supine, and general endotracheal anesthesia was induced. A right radial arterial line and a right internal jugular central venous catheter were placed. Pulmonary artery catheters were not routinely used. A median sternotomy was performed in standard fashion. The bypass conduits were harvested in the usual fashion. The pericardium was opened and the heart was suspended in the pericardial cradle. Carbon dioxide was infused into the chest to reduce the risk of air embolism. Each patient was heparinized to an activated clotting time of $>350$ seconds. Cardiopulmonary bypass was established using bicaval cannulation to allow the right atrial lesion set to be performed. The entire ablation procedure and the coronary bypass grafts were performed on cardiopulmonary bypass.

Before any ablation was performed, the pulmonary veins were dissected and controlled using umbilical tape. Pacing thresholds were obtained from each of the 4 pulmonary veins. A bipolar radiofrequency clamp was then used to isolate a cuff of atrial tissue encompassing the 2 sets of pulmonary vein orifices. Three sets of ablations were performed around the right and left pulmonary veins. Pacing was then performed from the pulmonary veins at 20 milliamperes to confirm electrical isolation of the pulmonary veins, also known as exit block. Further ablations were performed if necessary until conduction block was obtained. The left pulmonary veins were then isolated in a similar manner. 


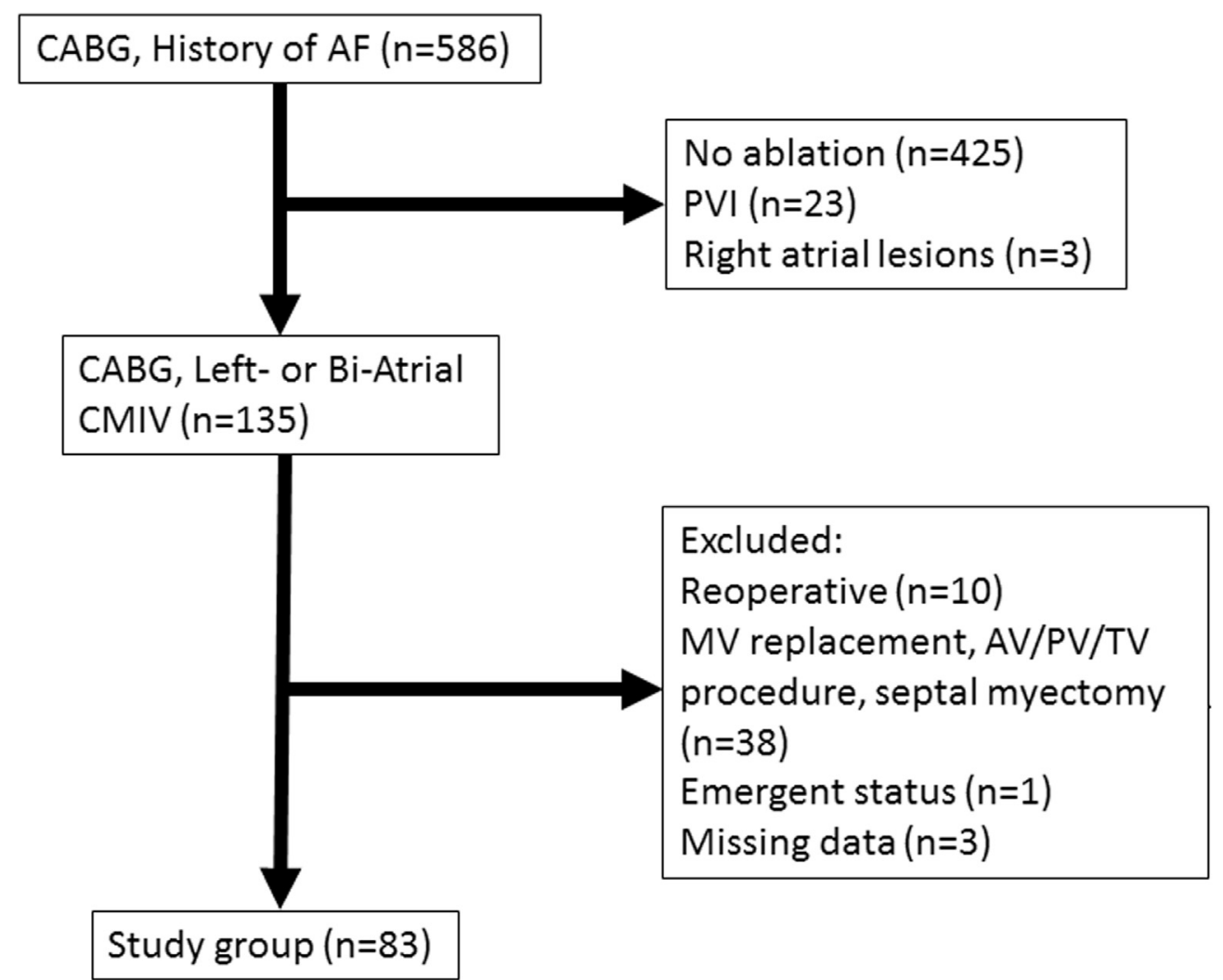

FIGURE 1. Consolidated Standards of Reporting Trials type patient flow diagram. $C A B G$, Coronary artery bypass grafting; $A F$, atrial fibrillation; $P V I$, pulmonary vein isolation; $C M I V$, Cox-max IV; $M V$, mitral valve; $A V$, aortic valve; $P V$, pulmonic valve; $T V$, tricuspid valve.

After the pulmonary vein isolation, the right atrial lesion set was performed as shown in Figure 2, A..$^{3,12}$ The right atrial lesion set was omitted in patients who had paroxysmal AF, left atrial size $<5.0 \mathrm{~cm}$, and no evidence of right atrial enlargement. Umbilical tapes were secured around the superior and inferior vena cava. A purse-string suture was placed at the base of the right atrial appendage. The bipolar radiofrequency clamp was introduced through this suture, and an ablation was made along the atrial free wall on the aortic side of the right atrial appendage. This lesion must lie at least $2 \mathrm{~cm}$ medial to the later lesion toward the superior vena cava to protect the sinoatrial node. Each right atrial radiofrequency ablation was performed at least 3 times to ensure conduction block. A longitudinal right atriotomy was then made from just above the interatrial septum to the atrioventricular groove near the free margin of the heart. Ablations were then made from the inferior aspect of the atriotomy up to the superior vena cava and down to the inferior vena cava. The ablation to the superior vena cava was kept as posterior as possible to avoid damage to the sinoatrial node. A linear cryoprobe was then used to make lesions from the superior end of the atriotomy toward the tricuspid valve annulus at the 2 o'clock position. The probe was palpated in the right ventricle before ablation. A final cryoablation was performed from the right atrial appendage purse-string suture down to the tricuspid annulus at the 10 o'clock position. Each cryoablation was performed for three minutes at $-60^{\circ} \mathrm{C}$. Closure of the right atrium was deferred until rewarming.

Antegrade and retrograde cardioplegia catheters were then inserted. The aorta was crossclamped, and cold blood cardioplegia was administered. The heart was retracted to expose the left atrial appendage. The left atrial appendage was then amputated. The remainder of the left atrial maze procedure was then performed on cardiopulmonary bypass with aortic crossclamping, as shown in Figure 2, $B$. The bipolar radiofrequency clamp was inserted through the orifice of the appendage, and an ablation was performed connecting the appendage to the left-sided pulmonary vein ablation line. The appendage was then closed using a running 4-0 polypropylene suture. A left atriotomy was made in Waterston's groove. The bipolar radiofrequency clamp was used to make 2 connecting lesions from the superior and inferior aspects of the atriotomy into the left superior and inferior pulmonary veins. The superior connecting lesion was omitted in 9 patients because these patients have been shown to have a high rate of recurrence. ${ }^{3}$ Each ablation was performed at least 3 times. The next line of ablation was performed with the bipolar radiofrequency clamp from the inferior aspect of the left atriotomy toward the mitral isthmus and across the coronary sinus. A bell-shaped reusable cryoprobe was used to complete the endocardial ablation line to the mitral annulus. A linear cryoprobe was then used to ablate the coronary sinus by way of the epicardium. If concomitant mitral valve repair was necessary, it was performed at this time. A left ventricular vent was placed and the left atrium was then de-aired and closed using a running 4-0 polypropylene suture.

After the CMIV lesions were completed, the coronary bypasses were performed in standard fashion. The aortic root was de-aired and the crossclamp was removed. At this time the right atriotomy was closed using a running 4-0 polypropylene suture. The patient was weaned from cardiopulmonary bypass, and the heart was defibrillated as necessary. The cannulas were removed and the chest was closed in standard fashion.

There were few variations in the CMIV procedure during the course of this case series. From 2002 to 2005 a lesion (the superior connecting lesion on the left atrium) was omitted. This unfortunately resulted in incomplete posterior left atrial isolation with a high rate of recurrent AF. The superior connecting lesion was omitted in 9 out of 83 patients $(11 \%)$ in the current series. If a patent foramen ovale was noted at the time of left atriotomy, it was closed; this occurred in 7 out of 83 patients $(8 \%)$ in this series. Concomitant mitral valve repair was performed in 24 out of 83 patients $(29 \%)$. 


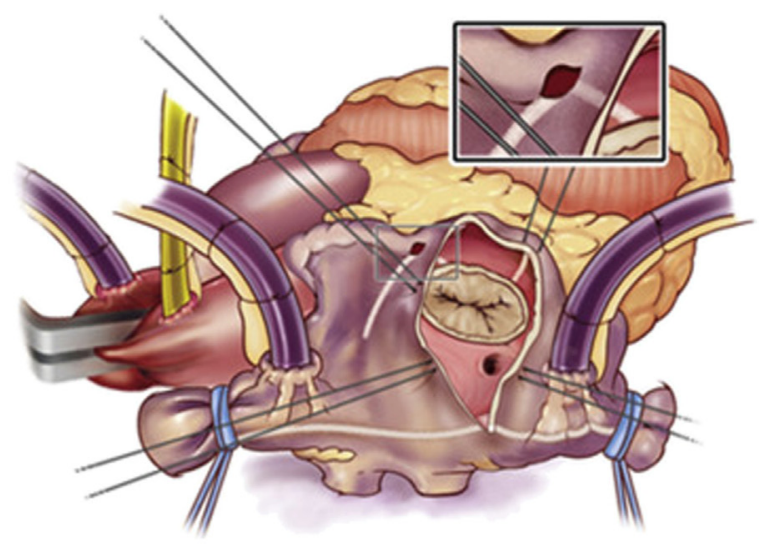

A Right Atrial Lesion Set

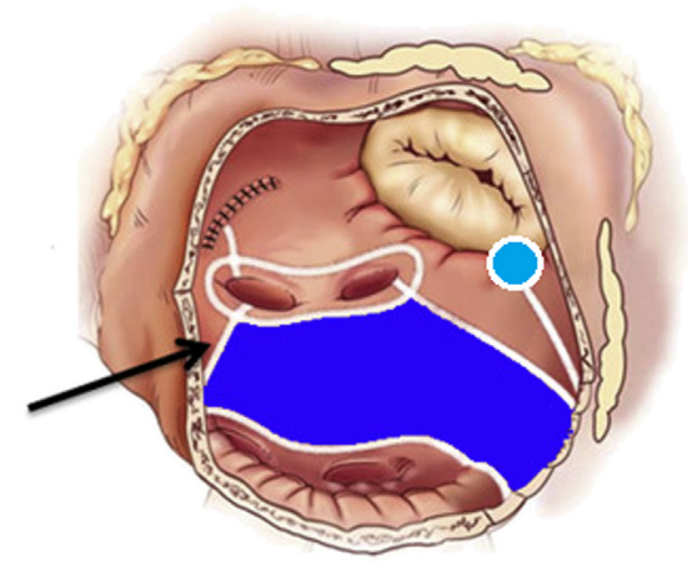

\section{B Left Atrial Lesion Set}

FIGURE 2. Atrial lesion sets for the Cox-maze IV procedure. ${ }^{3} \mathrm{~A}$, Right. $\mathrm{B}$, left. White lines denote bipolar radiofrequency ablation or linear cryoablation. A $T$-shaped cryoprobe is used at the mitral valve annulus (blue circle). The coronary sinus lesion is placed on the posterior aspect of the heart and is not shown here.

\section{Follow-up}

Rhythm follow-up was obtained at 1, 2, 3, 4, and 5 years via electrocardiogram, referring physician report, Holter monitor, or pacemaker interrogation. Holter monitor and pacemaker interrogation were defined as continuous monitoring. Freedom from AADs and anticoagulation (AC) were assessed by reviewing patients' medication lists at the time of follow-up visits. The primary end point assessed was freedom from atrial tachyarrhythmias (ATAs) and AADs at 1 to 5 years, regardless of whether continuous monitoring was used. Long-term survival was assessed by determining either the known date of mortality or the last date of contact with the patient. Patients were offered the opportunity to obtain follow-up care at our institution; some elected to follow-up with their referring cardiologist. Attempts were made to contact patients and their referring cardiologists to obtain missing follow-up data.

\section{Statistical Analysis}

Statistical analysis was performed using R version 3.3.2 (R Foundation for Statistical Computing, Vienna, Austria). Normally distributed data are expressed as mean \pm standard deviation. Nonnormally distributed data are expressed as median and interquartile range (IQR). The Shapiro-Wilk test was used to test continuous variables for normality; a $P$ value $<.1$ was considered significant for this purpose. Proportions are expressed as frequency and percentage unless otherwise noted. Freedom from ATAs, ATAs and AADs, and AC were determined by dividing the number of patients free by the number of patients with follow-up data at each time point. Patients who died or who were unavailable for follow-up were censored for this purpose. Patients who required catheter ablation were considered permanent failures. Ninety-five percent confidence intervals for these proportions were calculated. Overall survival was analyzed using the $\mathrm{R}$ survival package, and a Kaplan-Meier estimate of the survival function with $95 \%$ confidence limits was generated. Survival estimates are expressed as a point estimate with a $95 \%$ confidence interval.

Subgroup analyses were performed to compare patients who did receive mitral valve repair with those who did not and to compare patients with 1 -year follow-up data with those who did not return for follow-up. Student $t$ test was used for normally distributed continuous variables, as determined above. The Kruskal-Wallis test was used for nonnormally distributed continuous variables. The $\chi^{2}$ test was used for proportions.

\section{RESULTS}

\section{Preoperative Data}

Preoperative data are shown in Table 1. Several demographic factors in this patient population are notable. A majority of patients were men (70 out of 83 [84\%]), and the median patient age was 68 years. More than half of patients in the series were obese, with median body mass index of 30. Left ventricular function was normal or nearly normal in the majority of patients, with a mean ejection fraction of $52 \%$; despite this, 45 out of $83(54 \%)$ had New York Heart Association functional class III or IV heart failure symptoms. Nine of 83 patients $(11 \%)$ had a history of stroke.

\section{Operative Details}

Operative details, mortality, and complications are shown in Table 2. Median cardiopulmonary bypass time was 180 minutes (IQR, 159-218 minutes), and median aortic crossclamp time was 86 minutes (IQR, 73-108 minutes). The median intensive care unit length of stay was 3 days (IQR, 2-5 days), and the median hospital length of stay was 9 days (IQR, 8-13 days).

\section{Postoperative Complications}

Operative mortality was 3 out of $83(3.6 \%)$. Readmission occurred within 30 days in 18 out of 83 patients $(22 \%)$. The most common complications were ATAs (48 out of 83 [58\%]), prolonged ventilation (16 out of 83 [19\%]), and renal failure (12 out of $83[14 \%]$ ). Dialysis was required for 6 out of 83 patients $(7 \%)$. Postoperative pacemakers were required for 8 out of 83 patients $(9.6 \%)$.

\section{Follow-up}

Freedom from ATAs with and without AADs and freedom from $\mathrm{AC}$ are shown in Figure 1. At 1, 2, 3, 4, and 5 years, $79 \%, 75 \%, 64 \%, 71 \%$, and $72 \%$ of patients, respectively, were available for follow-up. Continuous monitoring was available for 32 out of 57 (56\%), 22 out 
TABLE 1. Preoperative data $(\mathbf{N}=\mathbf{8 3})$

\begin{tabular}{|c|c|}
\hline \multicolumn{2}{|l|}{ Demographic characteristic } \\
\hline Male gender & $7(84.3)$ \\
\hline Age, y & $68.00(62.00-75.50)$ \\
\hline Body mass index & $30.04(25.29-33.69)$ \\
\hline \multicolumn{2}{|l|}{ Left ventricular function } \\
\hline Ejection fraction & $0.52 \pm 0.13$ \\
\hline Previous myocardial infarction & $20(24.1)$ \\
\hline $\begin{array}{l}\text { New York Heart Association } \\
\text { functional class III or IV symptoms }\end{array}$ & $45(54.2)$ \\
\hline Number of diseased vessels & $2(1-3)$ \\
\hline Mitral valve repair & $24(28.9)$ \\
\hline \multicolumn{2}{|l|}{ Atrial fibrillation type } \\
\hline Paroxysmal & $37(44.6)$ \\
\hline Persistent & $13(15.7)$ \\
\hline Longstanding persistent & $33(39.8)$ \\
\hline Length of time in atrial fibrillation, mo & $24(4-60)$ \\
\hline \multicolumn{2}{|l|}{ Antiarrhythmia drugs* } \\
\hline Ic & $5(6.2)$ \\
\hline $\mathrm{II} \dagger$ & $55(67.9)$ \\
\hline III & $21(25.9)$ \\
\hline $\mathrm{IV} \ddagger$ & $23(28.4)$ \\
\hline $\mathbf{V} \S$ & $12(14.8)$ \\
\hline Failed catheter ablation & $11(13.3)$ \\
\hline Previous percutaneous coronary intervention $\|$ & $22(30.1)$ \\
\hline Number of grafts & $2(1-3)$ \\
\hline Left internal thoracic artery & $1(1-1)$ \\
\hline Saphenous vein graft & $1(1-2)$ \\
\hline Right internal thoracic artery & $0(0-0)$ \\
\hline Radial & $0(0-0)$ \\
\hline \multicolumn{2}{|l|}{ Cardiovascular comorbidity } \\
\hline Smoking history & $26(31.3)$ \\
\hline Hypertension & $67(80.7)$ \\
\hline Dyslipidemia & $68(81.9)$ \\
\hline Peripheral vascular disease & $15(18.1)$ \\
\hline Stroke & $9(10.8)$ \\
\hline Preoperative pacemaker & $6(7.2)$ \\
\hline \multicolumn{2}{|l|}{ Noncardiovascular comorbidity } \\
\hline Chronic lung disease & $18(21.7)$ \\
\hline Diabetes & $27(32.5)$ \\
\hline Renal failure & $5(6.0)$ \\
\hline
\end{tabular}

of $40(55 \%), 16$ out of $32(52 \%), 12$ out of $25(48 \%)$, and 11 out of $21(52 \%)$ patients at $1,2,3,4$, and 5 years, respectively. At 12 months, freedom from ATAs was $98 \%$ (56 out of 57), with $89 \%$ (51 out of 58) free from AF and off AADs. At 5 years, freedom from ATAs was $76 \%$ (16 out of 21 ), with 70\% (14 out of 20) free from AF and off AADs. Freedom from $\mathrm{AC}$ was similar to freedom from $\mathrm{AF}$ and off AADs; freedom from AC was $80 \%$ (46 out of 57) at 12 months and $70 \%$ (14 out of 20$)$ at 5 years.

\section{Survival}

Long-term survival is shown in Figure 3. Median survival could not be estimated because the majority of patients were
TABLE 2. Operative data, mortality, and complications $(\mathbf{N}=\mathbf{8 3})$

\begin{tabular}{lc}
\hline \multicolumn{1}{c}{ Variable } & Result \\
\hline Perfusion time, min & $180(159-217)$ \\
Crossclamp time, min & $86(73-108)$ \\
Operating room time, min* & $422(370-482)$ \\
Operative mortality & $3(3.6)$ \\
30-d readmission & $18(21.7)$ \\
Intensive care unit length of stay, h & $72(46-121)$ \\
Hospital length of stay, d & $9.00(8.00-13.00)$ \\
Complications & \\
Reoperation for bleeding & $5(6.0)$ \\
Postoperative stroke & $2(2.4)$ \\
Postoperative transient ischemic attack & $1(1.2)$ \\
Prolonged ventilation & $16(19.3)$ \\
Pneumonia & $10(12.0)$ \\
Intra-aortic balloon pump & $7(8.4)$ \\
Postoperative myocardial infarction & $1(1.2)$ \\
Mediastinitis & $0(0.0)$ \\
Deep venous thrombosis & $0(0.0)$ \\
Postoperative renal failure $\dagger$ & $12(14.5)$ \\
Postoperative dialysis & $6(7.2)$ \\
Postoperative pacemaker & $8(9.6)$ \\
Postoperative atrial fibrillation & $48(57.8)$ \\
\hline
\end{tabular}

Values are presented as median (interquartile range) or $n(\%) . * n=59 . \dagger$ Society of Thoracic Surgeons definition.

alive at final follow-up. Estimated survival was $87 \%$ $(80 \%-95 \%)$ at 1 year and $76 \%(66 \%-88 \%)$ at 5 years.

\section{Subgroup Analyses}

Patients who underwent CMIV-CABG with concomitant mitral valve repair $(\mathrm{n}=24)$ differed in several ways from patients who underwent CMIV-CABG alone $(\mathrm{n}=59)$. Patients undergoing concomitant mitral valve repair received fewer grafts (median 1 [1-2] vs 3 [2-3]; $P=.001)$. There were trends toward older age (75 years

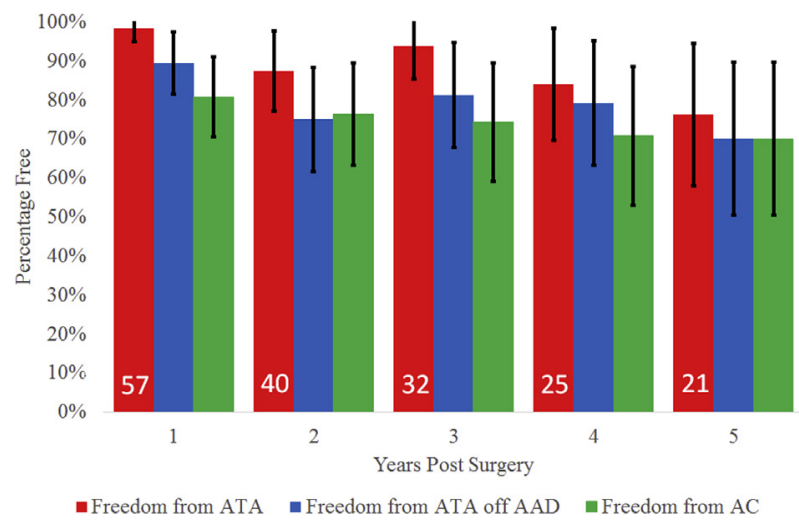

FIGURE 3. Freedom from atrial tachyarrhythmias (ATAs) regardless of anti-arrhythmia drugs (AAD) status (red), freedom from ATA and AAD (blue), and freedom from anticoagulation (AC) (green). White numbers denote number of patients with follow-up data. Error bars denote standard error. 


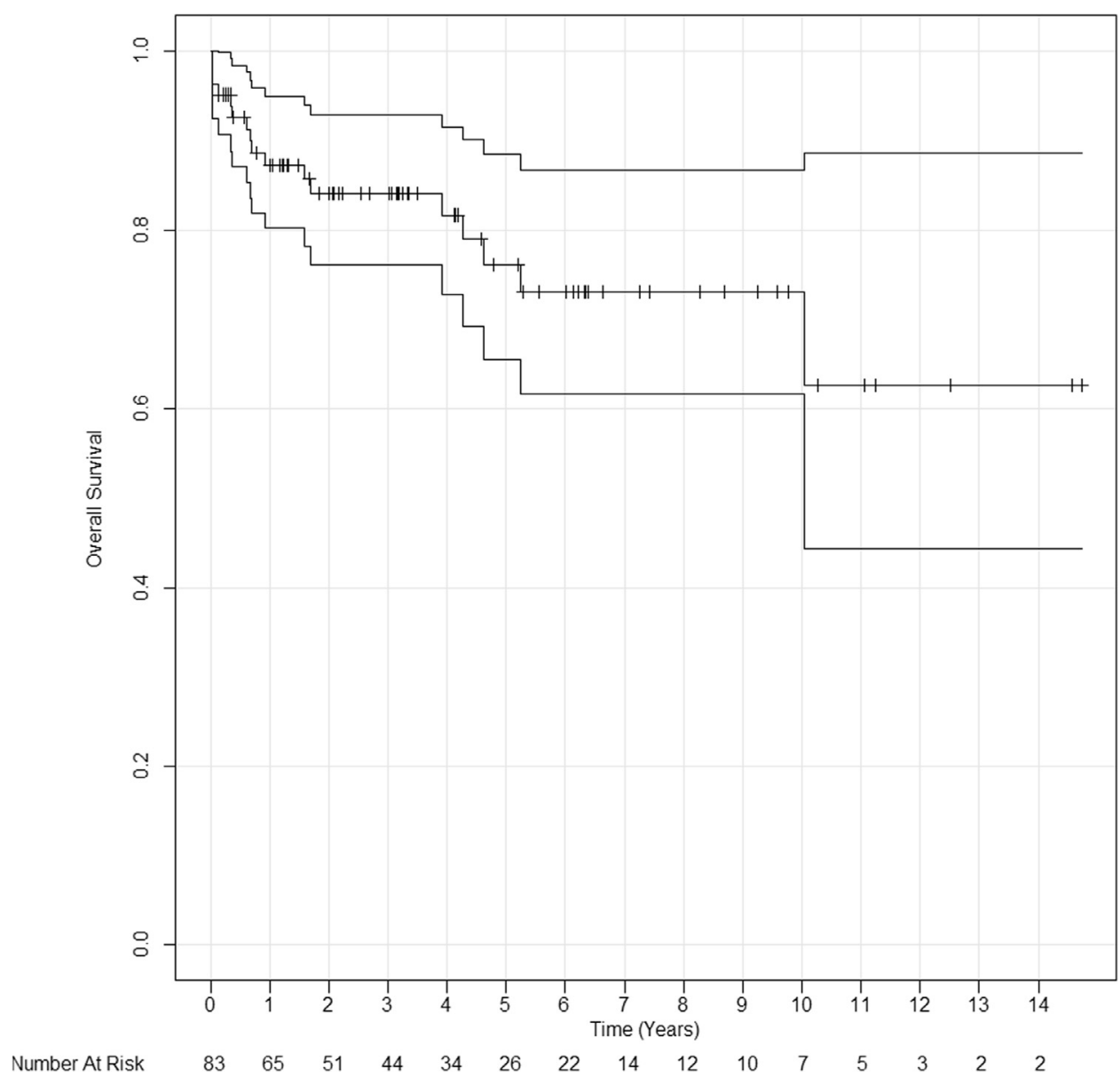

FIGURE 4. Kaplan-Meier overall survival curve after Cox-maze IV procedure with coronary artery bypass grafting, with $95 \%$ confidence interval.

[61-79 years] vs 67 years [63-74 years]; $P=.1$ ) and a higher rate of New York Heart Association functional class III or IV symptoms (17 out of 24 [71\%] vs 28 out of 59 [48\%]; $P=.09)$ in the mitral valve repair group.

Patients who died or did not return for follow-up at 1 year were censored from freedom from ATAs as depicted in Figure 4 . These patients had a lower preoperative ejection fraction $(0.48 \pm 0.15$ vs $0.54 \pm 11 ; P=.03)$, and had trends toward older age (73 years [IQR, 64-79 years] vs 67 years [IQR, 61-75 years]; $P=.07$ ) and a higher rate of tobacco use (12 out of $26[46 \%]$ vs 14 out of 57 [25\%]; $P=.09$ ).

\section{DISCUSSION}

This study was a single-institution retrospective cohort study of 83 patients with AF and coronary artery disease who underwent a CMIV procedure with concomitant CABG over a 13-year period. The CMIV lesion set, which mimics the cut-and-sew Cox-maze III lesion set with the use of bipolar radiofrequency clamps and cryoablation, was consistently applied in all patients in this series. A majority of patients in this series had persistent or longstanding persistent AF. These patients had high rates of preoperative comorbidities. This relatively high-risk cohort of patients underwent coronary artery bypass surgery and a CMIV procedure. Twenty-nine percent of patients also underwent mitral valve repair.

The short-term outcomes of CMIV and CABG reflect the fact that a relatively high-risk group of patients underwent an extensive operation. The most common complications were prolonged ventilation, renal failure, and pneumonia. These may be related to the relatively long cardiopulmonary bypass and crossclamp times and to the patients' baseline health. Many patients had early ATAs, although these are not typically considered a complication after surgery for AF. Despite the complication rate, there was a low mortality rate and discharge at a median of 9 days. At follow-up, freedom from ATAs and AADs, which is defined by the consensus statement, ${ }^{2}$ was $88 \%$ at 1 year and $70 \%$ at 5 years. Overall freedom from AATs regardless of AAD status was $98 \%$ at 1 year and $76 \%$ at 5 years. Freedom from $\mathrm{AC}$ was $80 \%$ at 1 year and $70 \%$ at 5 years. It should be noted that decisions regarding $\mathrm{AC}$ and $\mathrm{AADs}$ in the long term were often made by referring physicians and not by our team. 


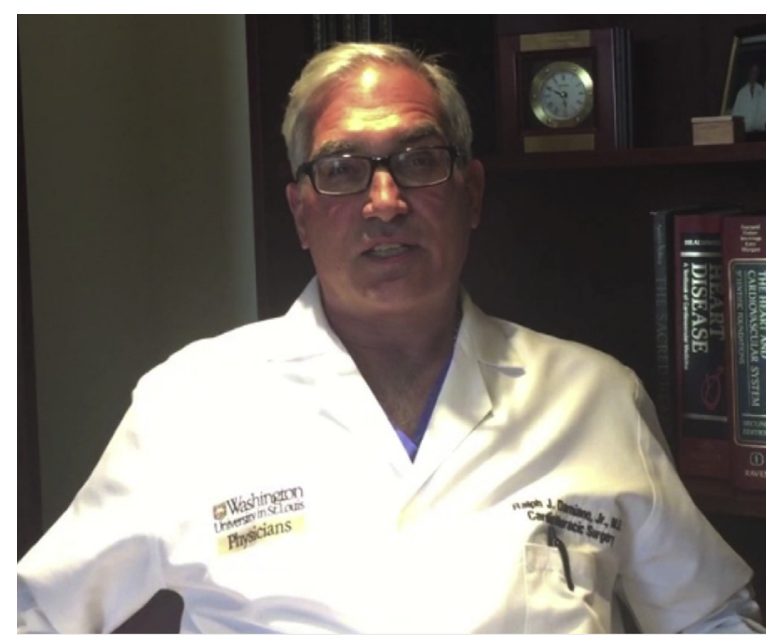

VIDEO 1. Ralph J. Damiano, Jr, MD, explains the relevance of the research in the context of the literature and the need for further studies of concomitant surgical ablation. Video available at: http://www. jtcvsonline.org/article/S0022-5223(17)30019-3/addons.

Few groups have published the results of CMIV and CABG procedures specifically, although there have been many reports of concomitant surgical ablation of AF. Ad and colleagues ${ }^{9}$ published the results of 95 patients who underwent a cryoablation-based Cox-maze procedure concomitant with aortic valve replacement and/or CABG in 2012. ${ }^{9}$ The rates of prolonged ventilation, pneumonia, and renal failure in the present series was higher than in the report by Ad and colleagues in 2012 ${ }^{9}$; however, only $7 \%$ of patients in the series presented by Ad and colleagues had New York Heart Association functional class III or IV symptoms compared with $54 \%$ in the present series, indicating that there may be a difference in these patient populations. Other authors, such as Cherniavsky and colleagues, ${ }^{11}$ have published the results of left atrial ablation procedures but did not use the CMIV lesion set or even a box lesion. The results of CMIV-CABG compare favorably with the results of catheter ablation; a recent meta-analysis including more than 6000 patients showed freedom from ATAs or reintervention at 12 months to be $64 \%$ after a single catheter ablation procedure. ${ }^{14}$

The results of this study compare favorably with our institution's experience with the Cox-maze procedure with concomitant CABG published in 2003 . $^{7}$ This was a series of 47 patients, 41 of whom underwent cut-and-sew Cox-maze III procedure and 6 of whom had microwave or bipolar radiofrequency ablation. The prior series had a $27 \%$ rate of major complications and a $2 \%$ operative mortality rate. ${ }^{7}$ The pacemaker rate in the present series $(10 \%)$ was lower than the $19 \%$ reported in 2003 . Median length of stay has decreased from 11 days to 9 days. At late follow-up in the 2003 series, $84 \%$ of patients were free from AF and AADs at mean 5.7 years; however, electrocardiogram or only symptomatic follow-up was used in the 2003 series. $^{7}$ The rate of renal failure in the CMIV-CABG population is higher than in the general CMIV cohort at our institution. The overall major complication rate in the full CMIV experience published in 2015 was $4 \% .^{3}$ It may be that patients with AF undergoing coronary bypass surgery represent a higher-risk group than those undergoing standalone CMIV operations or other concomitant surgical procedures. Freedom from ATAs at late follow-up in the CMIV-CABG cohort was similar to that reported in the full CMIV cohort. ${ }^{3}$

This study has several limitations. This was a retrospective study at a single institution, with most cases performed by a single highly experienced surgeon (RJD). Patient selection and referral patterns may have altered the patient population. These results may not be reflective of the outcomes of coronary bypass surgery with concomitant surgical ablation in all comers with AF. Additionally, despite the high volume of surgical ablation performed at our institution, only 161 patients received CABG with any surgical ablation during a 13-year period, and only 83 were eligible for inclusion in this case series. Furthermore, almost half of the follow-up in this series was performed without prolonged continuous monitoring. Consensus guidelines now recommend prolonged monitoring for the evaluation of ablation procedures for $\mathrm{AF}^{2}$ and Holter monitoring is our current practice. The use of noncontinuous monitoring for some follow-up and incomplete follow-up may have overestimated freedom from ATAs. Patients with missing follow-up had a lower preoperative left ventricular ejection fraction. Additionally, 7 patients in this series underwent only the left atrial portion of the CMIV procedure. These patients had paroxysmal AF, left atrial size $<5.0 \mathrm{~cm}$, and no evidence of right atrial enlargement. The sample size was too small to adequately compare results in this cohort with those who underwent a bi-atrial procedure. For additional discussion, see Video 1.

\section{CONCLUSIONS}

The addition of a CMIV procedure for patients with $\mathrm{AF}$ undergoing $\mathrm{CABG}$ has a high rate of nonfatal complications and is associated with a $70 \%$ success rate at 5 years. This single-center experience illustrates the need for multi-institutional studies and, ideally, randomized controlled trials to more clearly delineate the risks and benefits of concomitant surgical ablation, especially in high-risk patients.

\section{Conflict of Interest Statement}

M.R.S. has received travel funding from AtriCure, Inc. R.J.D. is a consultant for AtriCure, Inc, and a speaker for LivaNova, Inc, and CryoLife, Inc. He has received research funding and educational grants from AtriCure, Inc, and Edwards Lifesciences, Inc. All other authors have nothing to disclose with regard to commercial support. 


\section{References}

1. ElBardissi AW, Aranki SF, Sheng S, O’Brien SM, Greenberg CC, Gammie JS Trends in isolated coronary artery bypass grafting: an analysis of the Society of Thoracic Surgeons adult cardiac surgery database. J Thorac Cardiovasc Surg. 2012;143:273-81.

2. Calkins H, Kuck KH, Cappato R, Brugada J, Camm AJ, Chen SA, et al. 2012 HRS/EHRA/ECAS expert consensus statement on catheter and surgical ablation of atrial fibrillation: recommendations for patient selection, procedural techniques, patient management and follow-up, definitions, endpoints, and research trial design: a report of the Heart Rhythm Society (HRS) Task Force on Catheter and Surgical Ablation of Atrial Fibrillation. Developed in partnership with the European Heart Rhythm Association (EHRA), a registered branch of the European Society of Cardiology (ESC) and the European Cardiac Arrhythmia Society (ECAS); and in collaboration with the American College of Cardiology (ACC), American Heart Association (AHA), the Asia Pacific Heart Rhythm Society (APHRS), and the Society of Thoracic Surgeons (STS). Endorsed by the governing bodies of the American College of Cardiology Foundation, the American Heart Association, the European Cardiac Arrhythmia Society, the European Heart Rhythm Association, the Society of Thoracic Surgeons, the Asia Pacific Heart Rhythm Society, and the Heart Rhythm Society. Heart Rhythm. 2012;9:632-96.e21.

3. Henn MC, Lancaster TS, Miller JR, Sinn LA, Schuessler RB, Moon MR, et al. Late outcomes after the Cox maze IV procedure for atrial fibrillation. $J$ Thorac Cardiovasc Surg. 2015;150:1168-76. 1178.e1-2.

4. Henn MC, Lawrance CP, Sinn LA, Miller JR, Schuessler RB, Moon MR, et al Effectiveness of surgical ablation in patients with atrial fibrillation and aortic valve disease. Ann Thorac Surg. 2015;100:1253-9; discussion 1259-60.

5. Saint LL, Bailey MS, Prasad S, Guthrie TJ, Bell J, Moon MR, et al. Cox-maze IV results for patients with lone atrial fibrillation versus concomitant mitral disease. Ann Thorac Surg. 2012;93:789-94; discussion 794-5.

6. Gillinov AM, Gelijns AC, Parides MK, DeRose JJ Jr, Moskowitz AJ, Voisine P, et al. Surgical ablation of atrial fibrillation during mitral-valve surgery. $N$ Engl J Med. 2015;372:1399-409.
7. Damiano RJ Jr, Gaynor SL, Bailey M, Prasad S, Cox JL, Boineau JP, et al The long-term outcome of patients with coronary disease and atrial fibrillation undergoing the Cox maze procedure. J Thorac Cardiovasc Surg. 2003;126: 2016-21.

8. Ad N, Holmes SD, Pritchard G, Shuman DJ. Association of operative risk with the outcome of concomitant Cox maze procedure: a comparison of results across risk groups. J Thorac Cardiovasc Surg. 2014;148: 3027-33.

9. Ad N, Henry L, Hunt S, Holmes SD. Do we increase the operative risk by adding the Cox maze III procedure to aortic valve replacement and coronary artery bypass surgery? J Thorac Cardiovasc Surg. 2012;143: 936-44.

10. Pokushalov E, Romanov A, Corbucci G, Cherniavsky A, Karaskov A. Benefit of ablation of first diagnosed paroxysmal atrial fibrillation during coronary artery bypass grafting: a pilot study. Eur J Cardiothorac Surg. 2012; 41:556-60.

11. Cherniavsky A, Kareva Y, Pak I, Rakhmonov S, Pokushalov E, Romanov A, et al. Assessment of results of surgical treatment for persistent atrial fibrillation during coronary artery bypass grafting using implantable loop recorders. Interact Cardiovasc Thorac Surg. 2014;18:727-31.

12. Robertson JO, Saint LL, Leidenfrost JE, Damiano RJ Jr. Illustrated techniques for performing the Cox-Maze IV procedure through a right mini-thoracotomy. Ann Cardiothorac Surg. 2014;3:105-16.

13. Gaynor SL, Diodato MD, Prasad SM, Ishii Y, Schuessler RB, Bailey MS, et al. A prospective, single-center clinical trial of a modified Cox maze procedure with bipolar radiofrequency ablation. J Thorac Cardiovasc Surg. 2004;128: 535-42.

14. Ganesan AN, Shipp NJ, Brooks AG, Kuklik P, Lau DH, Lim HS, et al. Long-term outcomes of catheter ablation of atrial fibrillation: a systematic review and meta-analysis. J Am Heart Assoc. 2013;2:e004549.

Key Words: atrial fibrillation, arrhythmia therapy, ablation, coronary artery bypass grafting 